\title{
探讨小学数学教学中如何培养学生的数学思维
}

方三红

江西省武宁县第三小学

DOI:10.32629/jief.v2i11.2437

[摘 要] 小学数学课堂教学中的主要内容就是数学思维的训练, 教师既要分析和研究现阶段教学的实际情况, 又要从学生的兴趣爱好和教学 的具体需求出发, 优化整合教学的内容与方法。在数学教学活动中, 教师应该适当增加与生活相关的教学内容, 调动学生思考的主动性和学 习的积极性, 让学生知晓知识形成的过程, 获得数学思维能力的培养。本文针对如何在小学数学教学中培养学生的数学思维能力展开分析。 [关键词] 小学数学教学; 数学思维能力; 培养

中图分类号：G623 文献标识码：A

现代化教育的要求是培养学生独立思考、自主判断的思维能力, 增 强学生的综合素质。数学作为小学教育体系中的基础性课程, 集创新能 力、计算能力、思维能力于一体, 在学生的学习和生活中占据重要地位, 对学生敏捷性与灵活性的培养有积极意义。小学数学教师开展教学活动 时, 应该为学生营造良好的思维氛围, 为学生提供独立思考、自主学习 的空间, 从而调动学生的主观能动性, 使学生自主发现和解决问题, 实 现预期的教学目标。

\section{1 小学数学教学中培养学生数学思维能力的重要性}

数学思维是数学学习中的特定思维之一, 要求学生形象化数学中的 数字, 在此基础上进行数学运算。数学思维能力指的是学生学习数学过 程中, 对数学逻辑思维进行灵活运用, 借助想象空间, 对数学问题进行 推理和归纳, 进而全面分析与解决问题。现阶段, 小学数学教学受诸多 因素的影响, 让学生在新知识接受的能力方面存在显著的差别, 如有些 学生在掌握和运用数学知识方面相对笨拙, 有些学生则能快速掌握、灵 活运用所学的数学知识, 所以教师需要对每位学生的数学思维能力进行 培养。一般而言, 培养小学生的数学思维能力, 有利于让学生喜爱上数 学学习, 在学习中获得发散思维的发展, 增强学生思考和判断问题的能 力, 为今后的学习打好基础。由于数学学科具有抽象的意义和严密的逻 辑性, 而小学生正处于从感性思维过渡到理性思维的关键时期, 具备较 强的学习能力, 对于能力培养和新知接受的效果较好, 所以教师需要重 点关注学生的学习与理解, 积极培养学生的数学思维能力。可以说, 培 养小学生数学思维能力的目的在于让学生大胆创新, 形成良好的思维习 惯。在小学数学教学过程中, 教师能否有效培养学生的数学思维能力, 直接关系到学生未来对于知识的创新、理解、运用。

\section{2 小学数学教学中培养学生数学思维能力的路径}

2.1 创设教学情境

小学数学教学中经常使用的教学方法就是教学情境的创设, 即: 通 过引导来激发学生对未知事物的探究欲和好奇心, 让学生在真实的情境 中思考和解决问题。可以说, 创设教学情境的方式能充分激发学生的学 习兴趣, 帮助学生对抽象难懂的数学知识加以理解, 提高学习效率。好 的情境教学需要紧密联合学生与课堂, 让学生在创设的情境中深层次理 解教材内容, 这也是情境教学的目的。以 “折扣” 为例, 教师在具体讲 解时可以设计与超市促销相关的问题情境: 通过仔细观察, 超市里在做 什么活动? 你对 “打折” 有哪些了解? 小学生有超市购物的生活经历,
而折扣又是实际生活中常见的知识, 该情境的设计不仅能让学生产生学 习的兴趣, 又能激活学生已有的生活经验, 让学生明白: 打折就是商品 减价, 打折指的是现价是原价的百分之几, 将百分之几与打折相对应。 总之, 在教学中创设情境, 有利于学生更好地感知生活与数学之间的联 系, 在学习活动中带入积极的情感, 获得思维能力的发展。

\section{2 增加习题深度}

通常教师讲解完新课内容后, 会为学生布置习题, 让学生复习巩固 所学的知识。所以教师在学生完成基础练习后, 需要设计有深度的习题, 让学生大胆质疑所学知识和数学问题, 并通过小组合作讨论及自主思考 的方式来探究问题、归纳知识, 以此调动学生学习的主动性和思考的积 极性, 提高学生的数学思维能力。如讲解完 “圆面积计算” 的相关内容 后, 教师可以向学生展示下图的图形, 提出问题: 已知正方形的面積为 $16 \mathrm{~cm}^{2}$, 你能求出圆的面积吗? 该习题没有直接给出圆的半径, 学生在解 答过程中无法直接利用圆的面积公式 $\left(S=\pi r^{2}\right)$ 进行解答, 通过观察和 思考, 会发现正方形的边长恰好是圆的半径, 这时可以先求出正方形的 边长, 然后利用圆的面积公式进行计算。另外, 教师可以改变该习题的 条件, 即 “已知正方形的面积为 $13 \mathrm{~cm}^{2}$, 试求出圆的面积。” 学生不能按 照上述的方式计算, 这时教师需要引导学生转换思路, 如: 正方形的面 积公式为边长 $\times$ 边长, 而边长 $\times$ 边长就是半径 $\times$ 半径, 即 $r^{2}$, 将 $r^{2} \times \pi$ 就是圆的面积。可以说, 通过思维的变化, 数学问题能迎刃而解。

\section{3 结语}

综上言之, 小学数学教学的目的不只是引导学生掌握数学知识, 还 需引导学生掌握正确的学习方法。数学思维能力对学生今后的学习和成 长有着重要的作用, 所以教师在实际教学中要采取科学有效的措施来培 养学生的数学思维能力, 如注重数形结合、创设教学情境、善于联系生 活、增加习题深度、善于总结规律等, 这样方可激发学生学习的兴趣, 提高学生的综合素质与数学思维能力, 实现预期的教学目标。

\section{[参考文献]}

[1]顾慧霞,顾晨旭. 小学数学教学中如何培养学生的数学思维 [J]. 课 程教育研究,2018(41):142.

[2]卢维建. 浅谈小学数学教学中如何培养学生的数学思维能力 [J]. 中国校外教育,2018(25):67+117.

[3]王中琨.刍议农村小学数学综合实践活动教学策略 [J]. 新课 程,2020(29):84. 